\title{
T2 Hypointensity Aids in the Diagnosis of Intracranial Metastatic Adenocarcinoma
}

\author{
Khunsa Faiz, Alex Botsford, Namita Sinha, Simon Walling, \\ Jai Jai Shiva Shankar (1)
}

\begin{abstract}
Background: The T2 hypointensity has been suggested to be associated with intracranial metastatic adenocarcinomas (IMA). The purpose of our study was to determine the association of T2 hypointensity with IMA. Methods: All patients with pathologically confirmed metastatic brain tumors who had a magnetic resonance imaging (MRI) at our institution in the last 10 years were retrospectively assessed. Qualitative assessment of the lesions on MRI was done by two separate readers who were blinded to the pathological diagnosis. For qualitative assessment, the T2 hypointensity in the lesion was compared with the contralateral normal appearing white matter. Odds ratio, sensitivity, specificity, positive predictive value (PPV), and negative predictive value (NPV) were calculated. Results: Of 107 patients with intracranial metastasis, only 73 (40 females; 33 males; mean age 61 years) had MRI available for review. Of these, only 46 (25 females; 21 males; mean age 61 years) had pathologically proven IMA. T2 hypointensity was seen in $20 \%$ of IMA. The odds ratio of T2 hypointensity in IMA was 3 compared to nonadenocarcinomas but was not statistically significant $(\mathrm{p}=0.16)$. Intralesional hemorrhage was seen in 20 . When controlled for hemorrhage, the odds ratio for T2 hypointensity in IMA was 4.7. The specificity, sensitivity, PPV, and NPV for T2 hypointensity to diagnose IMA were $92 \%, 19 \%, 81 \%$, and $40 \%$, respectively. Conclusion: T2 hypointensity was seen only in $20 \%$ of IMA with an odds ratio of 4.7. T2 hypointensity showed a high specificity and PPV for diagnosis of IMA.
\end{abstract}

RÉSUMÉ : Utilisation des images pondérées en T2 dans le diagnostic des adénocarcinomes intracrâniens métastatiques. Contexte : Il a été suggéré qu'un hypo-signal révélé par des images pondérées en T2 pouvait être associé à la présence d'un adénocarcinome intracrânien métastatique (AIM). L'objectif de notre étude est donc de préciser la nature de cette association. Méthodes : Nous avons évalué rétrospectivement tous les patients de notre établissement chez qui l'on avait confirmé la présence de tumeurs cérébrales métastatiques au cours des dix dernières années. À noter que l'évaluation qualitative des lésions révélées par IRM a été effectuée en double aveugle par des individus qui ignorait tout du diagnostic pathologique. À cet effet, les hypo-signaux détectés par des images pondérées en T2 dans les lésions ont été comparés à la substance blanche de l'hémisphère controlatéral apparaissant normale. Pour ce faire, nous avons calculé le rapport des cotes (odds ratio), la sensibilité et la spécificité ainsi que la valeur prédictive positive (VPP) et la valeur prédictive négative (VPN). Résultats : Sur un total de 107 patients atteints de tumeurs cérébrales métastatiques, seulement 73 (40 femmes; 33 hommes; âge moyen: 61 ans) avait été soumis à des IRM disponibles pour révision. Sur ces 73 patients, seulement 46 (25 femmes ; 21 hommes ; âge moyen: 61 ans) étaient atteints d'un AIM pathologiquement avéré. Fait à souligner, des hypo-signaux révélés par des images pondérées en T2 ont été détectés dans $20 \%$ des cas d'AIM. Le rapport des cotes de ces hypo-signaux liés aux AIM était de 3 si on le compare au rapport des cotes des tumeurs non-AIM; cela dit, un tel rapport n'a pas été considéré statistiquement significatif $(p=0,16)$. Des signes d'hémorragie intra-lésionnelle ont été par ailleurs notés chez 20 patients. Une fois ce facteur hémorragique tenu en compte, le rapport des cotes de ces hypo-signaux liés aux AIM était de 4,7. Les pourcentages de spécificité, de sensibilité, de VPP et de VPN des hypo-signaux révélés par des images pondérées en T2 pour diagnostiquer des AIM ont été respectivement de 92\%,19\%,81\% et 40\%. Conclusion : Des hypo-signaux révélés par des images pondérées en T2 ont été détectés dans seulement $20 \%$ des cas d'AIM, le rapport des cotes étant de 4,7. En somme, ces hypo-signaux ont montré une spécificité et une VPP élevées dans le diagnostic des AIM.

Keywords: T2 hypointensity, Intracranial, Metastatic adenocarcinoma, MRI

doi:10.1017/cjn.2019.338

Can J Neurol Sci. 2020; 47: 210-213

\section{INTRODUCTION}

Brain metastases are the most common intracranial malignancy, affecting an average of $8.5-9.6 \%$ of all cancer patients. ${ }^{1}$ The distribution of primary malignancy varies greatly, ranging from approximately $1 \%$ of lymphoma patients to roughly $40 \%$ lifetime risk in patients with melanoma. ${ }^{2}$ The incidence proportion of brain metastases from adenocarcinoma lung is $26.8 \%,{ }^{3}$ which makes it second most common among the brain metastases, melanoma being the most common.

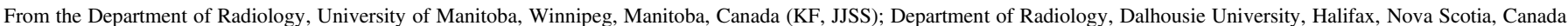

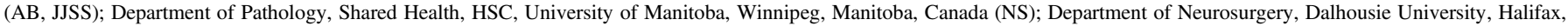
Nova Scotia, Canada (SW)

Received July 30, 2019. Final Revisions Submitted October 21, 2019. Date of Acceptance December 9, 2019.

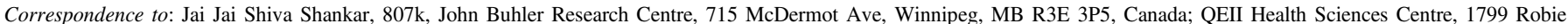
St, Halifax, NS B3H 3G1, Canada. Email: shivajai1@gmail.com 
Although some locations ${ }^{4}$ and magnetic resonance imaging (MRI) features ${ }^{5}$ are seen more commonly in certain primary malignancies, the primary source of metastases is difficult to determine on most MRI of brain. Determining the primary source and cell type in intracranial metastases could guide the search for the primary malignancy and may help tailor the management. ${ }^{6}$ We observed T2 hypointensity in metastatic brain lesions to be associated with primary adenocarcinomas. The purpose of our study was to determine the association of T2 hypointensity with intracranial metastatic adenocarcinomas (IMA).

\section{Methods}

The study was approved by institutional research ethics board (ROMEO file number - 1021905). A prospectively collected brain tumor database was retrospectively searched to find consecutive pathologically confirmed intracranial metastatic tumors. A computer-generated random table was used to randomly distribute 562 patients with metastatic tumors of brain in last 10 years (from 2007 to 2017), and the first 107 patients were included in the study. Patients were excluded from the study if their MRI was not available for review on our picture archiving and communication system (PACS).

\section{Image Analysis}

All MRIs were performed using Signa GE 1.5-T scanners. All images were analyzed on a PACS workstation. A number of lesions were recorded. In patients with multiple metastatic lesions, detailed analysis was performed only on the largest of the lesions. Qualitative assessment of the lesions was performed by two readers (AB and JJSS), who were blinded to each other and also blinded to the pathological diagnosis. For qualitative assessment, the T2 hypointensity in the lesion was compared with the contralateral normal appearing white matter. Quantitative analysis of T2 hypointensity with T2 relaxometry could not be done as none of the patients had T2-proton density sequence on their MRI for calculation of T2 relaxometry. Important confounders for $\mathrm{T} 2$ hypointensity-calcification and hemorrhage were also investigated. The presence of hemorrhage was assessed as more hypointensity or blooming on gradient or B0 of diffusion weighted imaging or hyperintensity on T1 weighted images, whenever available. Lesional calcification was evaluated on computed tomography (CT) scan of head done closer to the diagnostic MRI. Diagnosis of IMA on pathology was compared with the presence of T2 hypointensity.

\section{Signal Homogeneity}

T2 homogeneity was assessed qualitatively only using a threepoint grading system:

(a) Homogenously T2 hypointense (1): T2 hypointensity is present in $>75 \%$ of the lesion

(b) Heterogeneously T2 hypointense (2) : T2 hypointensity is present in $>25 \%$ of the lesion but $<75 \%$

(c) Homogenously T2 hyperintense (3): T2 hypointensity is present in $<25 \%$ of the lesion

Statistics-Stata 13.0 (StataCorp, College Station, TX, USA) was used for statistical analysis. Odds ratio for T2 hypointensity was calculated for IMA. Logistic regression was used to control

\section{Table 1: Patient demographics and anatomical distribution of intracranial metastatic adenocarcinomas and nonadenocarcinomas}

\begin{tabular}{|c|c|}
\hline Total number of patients & 73 \\
\hline Age (Mean; Range) & 61 years; $(33-78)$ \\
\hline Males & 33 \\
\hline Females & 40 \\
\hline Location of the largest lesion & Total number $(\%)$ \\
\hline Cerebellum & $24(32.8 \%)$ \\
\hline Frontal lobe & $19(26.0 \%)$ \\
\hline Parietal lobe & $13(17.8 \%)$ \\
\hline Temporal lobe & $10(13.7 \%)$ \\
\hline Parieto occipital lobe & $4(5.48 \%)$ \\
\hline Occipital lobe & $2(2.7 \%)$ \\
\hline Pineal Gland & $1(1.3 \%)$ \\
\hline Primary site of metastatic adenocarcinoma & Number of the lesions \\
\hline Lung & 24 \\
\hline Breast & 9 \\
\hline Colon & 7 \\
\hline Kidney & 3 \\
\hline Esophageal & 1 \\
\hline Bladder & 1 \\
\hline Unknown primary & 1 \\
\hline Primary site of metastatic nonadenocarcinoma & Number of the lesions \\
\hline Lung & 9 \\
\hline Melanoma & 9 \\
\hline Lymphoma & 2 \\
\hline Neuroendocrine & 2 \\
\hline Clear cell & 1 \\
\hline Sarcoma & 1 \\
\hline Atrial sarcoma & 1 \\
\hline Esophagus & 1 \\
\hline Poorly differentiated & 2 \\
\hline
\end{tabular}

for confounding effect of intralesional hemorrhage. Sensitivity, specificity, positive predictive value (PPV), and negative predictive value (NPV) were calculated. Interobserver agreement was assessed using kappa statistics. A p value $<0.05$ was considered statistically significant.

\section{Results}

Of 107 patients with intracranial metastases, only 73 (40 females, 33 males; mean age -61 years) had MRI for review. Detailed demographic and lesion characteristics are summarized in Table 1. Solitary brain metastasis was seen in $83.5 \%$ and multiple lesions were seen in $16.4 \%$.

Only three patients had intralesional calcification on CT, none of which showed T2 hypointensity. Hemorrhage was seen in eight patients on $\mathrm{CT}$, and four of these had T2 hypointensity, of which, three were adenocarcinomas. On T1WI, 13 lesions had hemorrhage, and only 4 of these demonstrated T2 hypointensity, 


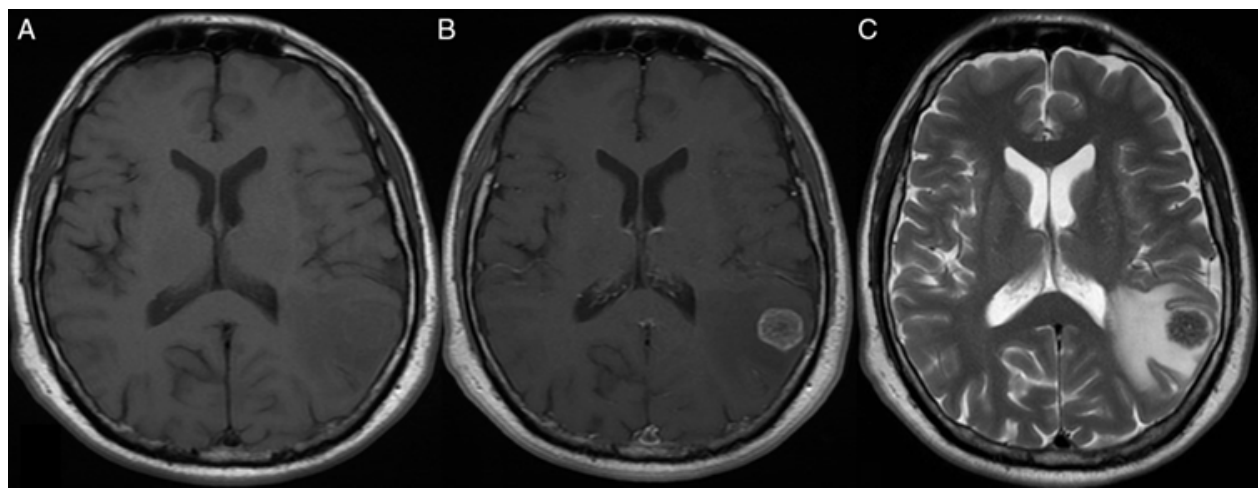

Figure 1: Adenocarcinoma metastasis from Colon. (A) T1 hypointense left parietal mass showing homogenous enhancement on (B) post gadolinium T1 image. (C) T2 hypointensity was seen in the lesion with surrounding edema. No hemorrhage/calcification was seen in this case on CT scan.

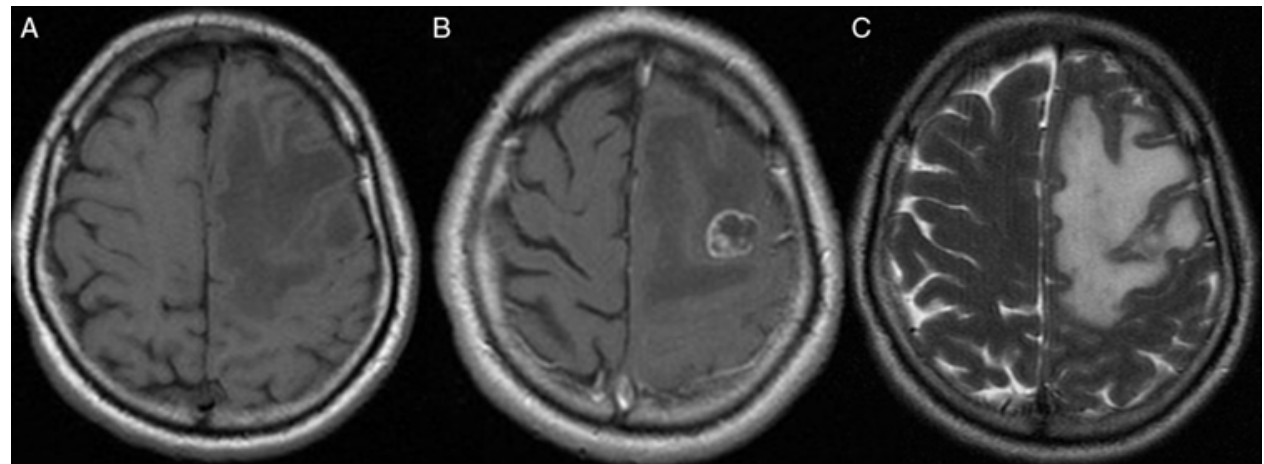

Figure 2: Squamous cell carcinoma metastasis from lung. (A) T1 isointense left parietal mass showing heterogeneous enhancement on post gadolinium T1 images (B). (C) This appeared heterogeneous on T2 images with surrounding edema.

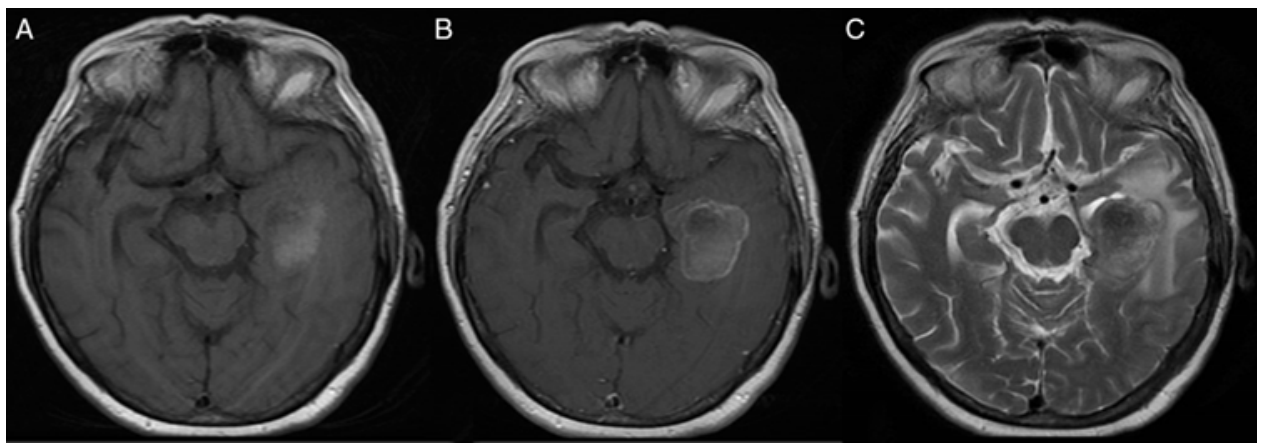

Figure 3: Nonadenocarcinoma metastasis from Neuroendocrine tumor. (A) T1 hyperintense left temporal lobe mass showing peripheral rim enhancement on $(B)$ post gadolinium T1 image. (C) T2 image shows that the mass is heterogeneously hypointense with surrounding edema and mass effect on the brainstem.

of which, 3 were adenocarcinomas. B0 of diffusion weighted imaging showed hemorrhage in 15 patients and 4 had T2 hypointensity, of which, 3 were adenocarcinomas. Gradient images were performed only in five patients - two patients showed evidence of blood products, but none showed T2 hypointensity - one was an adenocarcinoma and the other was nonadenocarcinoma on pathology.

T2 hypointensity was seen in only $15 \%$ of all metastases. Of the 46 pathologically proven IMA, 9 (20\%) showed T2 hypointensity (Figure 1). Of the 27 nonadenocarcinomas (5 squamous and 22 others), only 2 (7.4\%) showed T2 hypointensity (Figure 2). The odds ratio of T2 hypointensity in IMA was 3 compared to nonadenocarcinomas but was not statistically significant $(\mathrm{p}=0.16)$. Among those lesions showing T2 hypointensity, $82 \%$ were IMA and only $18 \%$ were nonadenocarcinomas. MRI evidence of blood products was seen in 20 patients, 10 each of IMA and nonadenocarcinomas and only 6 showed T2 hypointensity (Figure 3 ). When controlled for the 
presence of hemorrhage, IMA had an odds ratio of 4.7 to show T2 hypointensity $(\mathrm{p}=0.08)$.

The specificity, sensitivity, PPV, and NPV for T2 hypointensity to diagnose IMA were $92 \%, 19 \%, 81 \%$, and $40 \%$, respectively.

\section{DISCUSSION}

Our study is the first study to compare IMA with other intracranial metastases for $\mathrm{T} 2$ hypointensity. We found that $\mathrm{T} 2$ hypointensity is infrequently seen (only in 15\%) in intracranial metastatic lesions. IMA had higher odds (an odds ratio of 3 ) of showing T2 hypointensity. Blood products are potential confounders as these can show T2 hypointensity. After controlling for the presence of hemorrhage, IMA had much higher odds (an odds ratio of 4.7) to show T2 hypointensity. The presence of T2 hypointensity was highly specific $(95 \%)$ and had very high PPV $(81 \%)$ for the diagnosis of IMA.

Brain metastases from different primary sources behave differently in terms of systemic manifestations and response to treatment. Recognizing the primary tumor is very crucial for the management of intracranial metastases. ${ }^{7}$ MRI may give us diagnostic clues for the primary tumor in some cases such as melanomas that appear T1 hyperintense and mucinous metastases that may appear T2 hypointense. ${ }^{8}$ Most other cerebral metastases appear T2 hyperintense compared to white matter. ${ }^{9,10}$ Egelhof et al. found that the metastatic gastrointestinal adenocarcinomas to the brain showed T2 hypointensity. They proposed that the T2 hypointensity was the result of preferential T2 shortening caused by intralesional protein in the form of mucin. ${ }^{11}$ Conversely, Carrier et al., in their study of 15 patients, found no correlation between the presence of mucin and $\mathrm{T} 2$ hypointensity. ${ }^{12}$ Oshiro et al suggested, in 24 patients, T2 hypointensity of IMA is the result of relatively shorter $\mathrm{T} 2$ relaxation time of the primary tissue of origin. ${ }^{13}$ Unlike our study, none of these studies compared the T2 hypointensity of IMA with intracranial nonadenocarcinomas metastases. Although the exact pathogenesis of $\mathrm{T} 2$ hypointensity in IMAs remains uncertain, our study further provides evidence for association of T2 hypointensity with IMA even after controlling for the confounding effect of the presence of blood products.

\section{Limitation of the Study}

Our study was limited due to its retrospective nature. Almost one-third of our patients were excluded due to unavailability of their MRI. This resulted in a selection bias and limits the generalizability of our results. This was primarily due to the nonavailablity of MRIs in patients who were referred to our tertiary care center from other centers. However, random distribution of patients in our series may have reduced some of this selection bias. Our study with 73 patients is the largest to study T2 hypointensity in IMA; nevertheless, this is a relatively smaller series. Higher odds ratios favor positive association of T2 hypointensity with IMA even when $\mathrm{p}$ values showed only a trend toward significance.

\section{Conclusion}

In IMA, T2 hypointensity was relatively uncommon, but when present showed a high specificity and PPV.

\section{CONFLICT OF InTEREST}

The authors declare that they have no conflicts of interest.

\section{Ethical Approval}

All procedures performed were in accordance with the ethical standards of the institutional and/or national research committee and with the 1964 Helsinki declaration and its later amendments or comparable ethical standards.

\section{INFORMED CONSENT}

Informed consent was obtained from all individual participants included in the study.

\section{Statement of Authorship}

$\mathrm{KF}$ - Draft and revise the manuscript and final approval. $\mathrm{AB}$ - Data acquisition and manuscript preparation. NS - Design of study, data acquisition, and final approval. SW - Conceptualized the project, design of study, data acquisition, and final approval. JJSS - supervision, design of study, data analysis and interpretation, revision of manuscript, and final approval.

\section{REFERENCES}

1. Nussbaum ES, Djalilian HR, Cho KH, Hall WA. Brain metastases. Histology, multiplicity, surgery, and survival. Cancer. 1996;78(8): 1781-8.

2. Schouten LJ, Rutten J, Huveneers HAM, Twijnstra A. Incidence of brain metastases in a cohort of patients with carcinoma of the breast, colon, kidney, and lung and melanoma. Cancer. 2002; 94(10):2698-705.

3. Cagney DN, Martin AM, Catalano PJ, et al. Incidence and prognosis of patients with brain metastases at diagnosis of systemic malignancy: a population-based study. Neuro Oncol. 2017;19(11): 1511-21.

4. Kim Y-J, Lee SK, Cho MK, Kim Y-J. Intraventricular glioblastoma multiforme with previous history of intracerebral hemorrhage: a case report. J Korean Neurosurg Soc. 2008;44(6):405-8.

5. Svolos P, Kousi E, Kapsalaki E, et al. The role of diffusion and perfusion weighted imaging in the differential diagnosis of cerebral tumors: a review and future perspectives. Cancer Imaging. 2014;14:20.

6. Shonka N, Venur VA, Ahluwalia MS. Targeted treatment of brain metastases. Curr Neurol Neurosci Rep. 2017;17(4):37.

7. Sperduto PW, Chao ST, Sneed PK, et al. Diagnosis-specific prognostic factors, indexes, and treatment outcomes for patients with newly diagnosed brain metastases: a multi-institutional analysis of 4,259 patients. Int J Radiat Oncol Biol Phys. 2010;77(3):655-61.

8. Zakaria R, Das K, Bhojak M, Radon M, Walker C, Jenkinson MD. The role of magnetic resonance imaging in the management of brain metastases: diagnosis to prognosis. Cancer Imaging. 2014;14:8.

9. Delmaire C, Savatovsky J, Boulanger T, et al. [Brain metastases imaging]. Cancer Radiother. 2015;19(1):16-9.

10. Gaudino S, Di Lella GM, Russo R, et al. Magnetic resonance imaging of solitary brain metastases: main findings of nonmorphological sequences. Radiol Med. 2012;117(7):1225-41.

11. Egelhoff JC, Ross JS, Modic MT, Masaryk TJ, Estes M. MR imaging of metastatic GI adenocarcinoma in brain. AJNR Am J Neuroradiol. 1992;13(4):1221-4.

12. Carrier DA, Mawad ME, Kirkpatrick JB, Schmid MF. Metastatic adenocarcinoma to the brain: MR with pathologic correlation. AJNR Am J Neuroradiol. 1994;15(1):155-9.

13. Oshiro S, Tsugu H, Komatsu F, et al. Metastatic adenocarcinoma in the brain: magnetic resonance imaging with pathological correlations to mucin content. Anticancer Res. 2008;28(1B):407-13. 